\title{
Association of ATP-Binding Cassette Transporter A1 G1051A Polymorphism with Type 2 Diabetes, Lipids and Coronary Artery Disease in Tunisian Population
}

\author{
Chaaba Raja ${ }^{1 *}$, Mehri Sounira ${ }^{1}$, Beizig Nadia ${ }^{1}$, Ben Ayed Nadia ${ }^{1}$, Hammami Sonia ${ }^{1,2}$, Ben Hamda Kholdoun ${ }^{1,3}$ \\ and Hammami Mohamed ${ }^{1}$
}

${ }^{1}$ Lab-NAFS "Nutrition-Functional Food \& Vascular Health", Tunisia

${ }^{2}$ Department of Internal Medicine, CHU Fattouma Bourguiba, Tunisia

${ }^{3}$ Department of Cardiology, CHU Fattouma Bourguiba, Tunisia

Submission: July 03 2019; Published: August 06, 2019

*Corresponding author: Chaaba Raja, Lab-NAFS “Nutrition-Functional Food \& Vascular Health”, Tunisia

\begin{abstract}
Background: ATP-binding cassette transporter A1 (ABCA1) plays a key role in lipoprotein metabolism. This metabolism is perturbated in type 2 diabetes, and was associated with coronary artery disease (CAD). Thus, we aim to study the association between ABCA1 polymorphism and diabetes and the possibility to develop coronary artery disease in those patients.

Methods: One hundred twenty-three type 2 diabetic patients were compared to 49 healthy subjects. Lipid parameters were measured using enzymatic ways. Genotypic polymorphism was studied using RFLP-PCR. Results: The GG genotype is more frequent in diabetic patients and was associated with increased risk of diabetes ( $41.7 \%$ vs $27.1 \%$ in diabetic and healthy subjects respectively; OR=1.92 [0.91-3.93], $\mathrm{p}=0.052$ ). However, no association of the polymorphism and CAD was shown in type diabetic group. This genotype is also associated with higher cholesterol and LDL cholesterol concentrations in all diabetics, with higher apo B level only in diabetics without CAD, and with lower level of apo A1 in diabetics with CAD. Furthermore, the decreased level of HDL cholesterol in type 2 diabetics with CAD compared to those without CAD was shown only in GG genotype.
\end{abstract}

Conclusion: Our results suggest that ABCA1(G1051A) polymorphism can be considered as risk factor for type 2 diabetes but not as risk factor for CAD in this group.

Keywords: ATP-binding Cassette Transporter A1; Coronary artery disease; Lipids; G1051A polymorphism; Type 2 diabetes; Cholesterol concentrations; Polymorphism; Hypertriglyceridemia; Atherosclerosis; Cardiovascular disease; Coronography

Abbreviations: CAD: Coronary Artery Disease; T2DM: Type 2 Diabetic Patients; OR: Odds Ratio: D: Diabetics

\section{Introduction}

The interaction between diabetes and lipid perturbation is controversial. First, lipid perturbation could be a risk factor for diabetes. The relevant interaction between glucose and lipid metabolism [1], also the positive relationship between statin therapy and diabetes risk [2] reinforced the idea. Second, lipid perturbation could be the result of diabetes because of defects in insulin action and hyperglycemia [3]. The main feature of lipid profile in type 2 diabetes is hypertriglyceridemia, low HDL cholesterol and small and dense LDL which was associated with increased cardiovascular disease incidence [4]. In fact, in type 2 diabetes the reverse cholesterol transport is perturbated.
In reverse cholesterol transport, the excess cholesterol present in peripheral tissues including the cells of the arterial wall is returned to the liver for elimination through the biliary system. ATP-binding cassette transporter A1 (ABCA1) plays a key role in this way [5]. This protein transports cholesterol, phospholipids and other lipophilic molecules across the cell membrane, where they are removed by apolipoproteins from HDL [6]. ABCA1 is involved in the assembly of free cholesterol with apolipoprotein $\mathrm{AI}$, thus playing an important role in the biogenesis of HDL particles. Various mutations and SNPs affecting the ABCA1 gene have been identified as the molecular basis of Tangier disease and familial hypoalphalipoproteinemia, characterized by deficient 


\section{Current Research in Diabetes \& Obesity Journal}

cholesterol efflux and reduced plasma HDL-C, than an increased risk of atherosclerosis [7]. ABCA1 is thus a good candidate for the study of dysfunctions of lipid metabolism and cardiovascular risk. In addition, many variants of ABCA1 have been associated with clinical and biochemical phenotypes, including changes in plasma HDL levels [8,9].

The single nucleotide polymorphism R219K has been associated with protection against coronary heart disease. This protective effect appears to be related to an increase in HDL-C $[10,11]$, but these results have not been replicated in all studies [12] due to ethnic and environmental differences. In this context, to clarify the effect of ABCA1 on the Tunisian population, we evaluated the impact of this polymorphism on lipid parameters and its potential association with diabetes and coronary artery disease.

\section{Patients and Methods}

\section{Patients}

One hundred twenty-three unrelated patients were recruited from the cardiology and internal medicine departments of University Hospitals in Monastir. All clinical, anthropometric and coronarographic information was compiled for each patient included in the study. They were divided into two groups: Group 1 (DC) $(\mathrm{n}=72)$ : Type 2 diabetic patients with coronary artery disease (CAD) and Group 2 (D) $(n=51)$ : subjects with type 2 diabetes without coronary artery disease. Diabetes was defined according to the criteria of the American Diabetes Association [13]. The coronary heart problem was defined by a previous expectation of stable angina, or a myocardial infarction with or without an ST segment. The coronary problem is confirmed by coronography. Healthy group (T): 49 control subjects were recruited from Orthopedic Department of University Monastir Hospital. They are healthy without a history of cardiovascular disease. Written or verbal informed consent were obtained from all patients and controls before the study in 2010. All written informed consent was not possible because the majority of eligible subjects in our study were illiterate. All subjects (healthy, diabetic patients with and without CAD) examined with medical treatment to disrupt lipid metabolism, renal or hepatic impairment, and thyroid problems were excluded from this study.

Table 1: Clinical and Biochemical Characteristics of Different Groups (Control, Diabetic Patients and Diabetic Patients with Coronary Artery Disease (CAD)).

\begin{tabular}{|c|c|c|c|c|}
\hline & Control N = 49 & Type 2 Diabètes N = 51 & Type 2 Diabetes with CAD N = 72 & P (ANOVA) \\
\hline Sex (M/F) & $18 / 31(36,7 \%) /(63,3 \%)$ & $21 / 30(41,2 \%) /(58,8 \%)$ & $51 / 21(70,8 \%) /(29,2) * *$ & $<0,001$ \\
\hline Age (years) & $49,53 \pm 6,596$ & $51,27 \pm 6,155$ & $56,08 \pm 7,071 *$ 。 & $<0,001$ \\
\hline Menopause (\%) & $7(25 \%)$ & $17(58,6 \%) \cdot$ & $17(85 \%)^{* *}$ 。 & $<0,001$ \\
\hline Menopause duration (years) & $3,71 \pm 2,21$ & $6,32 \pm 4,15$ & $12,81 \pm 8,47 *^{*}$ & 0,002 \\
\hline BMI (Kg /m2) & $28,31[18,75-31,17]$ & $27,52[24,85-31,69]$ & $28,94[26,23 ;-31,36] \circ$ 。 & 0,38 \\
\hline Dyslipidemia (\%) & $4(8,2 \%)$ & $15(29,4 \%) \cdot$ & $22(32,8 \%)^{*}$ 。 & 0,006 \\
\hline ssHTA (\%) & $2(4,2 \%)$ & $8(16 \%) \cdot$ & $27(39,7 \%)^{* *}$ 。 & $<0,001$ \\
\hline Duration of diabètes (years) & Newly discovered & $8,02 \pm 5,68$ & $6,47 \pm 5,59$ & 0,32 \\
\hline
\end{tabular}




\section{Current Research in Diabetes \& Obesity Journal}

\begin{tabular}{|c|c|c|c|c|}
\hline $\begin{array}{c}\text { Duration of Dyslipidemia } \\
\text { (years) }\end{array}$ & Newly discovered & $2[1-5]$ & $1[0-4]$ & 0,86 \\
\hline Duration of HTA (years) & & $8,5[2,5-10]$ & $3[0-13,75]$ & 0,81 \\
\hline Smoking (\%) & $34(69,4 \%)$ & $40(78,4 \%)$ & $53(73,6 \%)$ & 0,588 \\
\hline Glucose (mmol /l) & $5,29 \pm 0,53$ & $10,46 \pm 3,19 \bullet \bullet$ & $11,16 \pm 3,59^{* *}$ 。 & $<0,001$ \\
\hline Proteinuria (g/24h) & 0 & $0,001[0-0,09] \bullet$ & $0,02[0,001-0,14]^{*}$ & 0,12 \\
\hline Creatinemia (mmol/l) & $90[80-98,75]$ & $87,75[79-96,5]$ & {$[87-114]^{* *}$ 。 } & $<0,001$ \\
\hline
\end{tabular}

Significant Difference Between D and DC * $p<0.05 * * p<0.01$

Significant Difference Between T et $D \cdot p<0.05 \cdots p<0.01$

Significant Difference Between T et DC $\mathrm{p}<<0.05$ 口о $<<0.01$

Results

\section{Anthropometric, clinical and biological characteristics of the studied groups}

The clinical and biochemical characteristics of the subjects participating in our study are summarized in Table 1 . The coronary diabetic (DC) subjects have a mean age greater than that of the controls (T) and diabetics (D), in addition, the majority of coronary diabetic subjects are male. Also, it is emphasized that DC are more obese than controls. In addition, we note that the percentage of menopausal women is significantly higher in patients ( $>58.6 \%$ ) and the most important menopausal duration is found in women with coronary heart disease. Moreover, the clinical examination revealed the risk factors (hypertension and dyslipidemia) significantly more present in the patients compared to the controls.

Biological parameters tell us more about the complication of diabetes. In fact, the comparison between diabetics with and without CAD disease showed that there is a significant elevation in coronary diabetics in terms of proteinemia and a very significant level of serum creatinemia.

Table 2: Lipid Profile Variations in Patients Compared to Healthy Subjects.

\begin{tabular}{|c|c|c|c|c|}
\hline & Control & Type 2 Diabètes & Type 2 Diabètes with CAD & P (ANOVA) \\
\hline Cholesterol (mmol /l) & $4,81 \pm 1,09$ & $5,11 \pm 0,95$ & $5,04 \pm 1,06$ & 0,32 \\
\hline HDLcholesterol (mmol/l) & $0,88 \pm 0,24$ & $0,8 \pm 0,23 \bullet$ & $0,71 \pm 0,22$ - & 0,07 \\
\hline LDLcholesterol (mmol/l) & $3,23 \pm 1,01$ & $3,34 \pm 0,82$ & $3,3 \pm 0,84$ & 0,82 \\
\hline Apo B (g/l) & $1,01 \pm 0,26$ & $1,06 \pm 0,27$ & $1,03 \pm 0,22$ & 0,62 \\
\hline Apo A1 (g /l) & $1,36[1,25-1,5]$ & $1,35[1,17 ;-1,51]$ & $1,30[1,09-1,46]$ & 0,15 \\
\hline Triglycerides (mmol/l) & $1,24[0,95-1,71]$ & $1,67[1,29-2,76] \cdot$ & $1,9[1,53-2,60] \circ * *$ & $<0,001$ \\
\hline
\end{tabular}

Significant Difference Between D and DC * $p<0.05$

Significant Difference Between $T$ et $D \cdot p<0.05$

Significant Difference Between T et DC $₫ p<0.05$ a $p<0.01$

Lipid, lipoprotein and apolipoprotein characteristics of the three studied groups

By comparing the concentration of lipids, lipoprotein and apolipoprotein in different groups (controls, diabetics and diabetics with CAD), a variation of some parameters was noted (Table 2). TG concentration differed significantly between the 3 groups, with significant elevation in D and DC compared to $\mathrm{T}$ and between diabetic patients with and without CAD. HDL cholesterol concentration is significantly lower in diabetics and diabetics with CAD compared to healthy subjects. However, the

Table 3: Genotypic and Allelic Frequencies of ABCA1 Polymorphism in Different Groups

\begin{tabular}{|c|c|c|c|}
\hline & Control $(\mathrm{n}=49)$ & Diabetics $(\mathrm{n}=51)$ & Diabetics with CAD (n=72) \\
\hline Genotypic Frequency & & & $30(41,18 \%)$ \\
\hline GG & $13(26,5 \%)$ & $21(58,82 \%)$ & $29(40,2 \%)$ \\
\hline GA & $35(71,5 \%)$ & $0(0 \%)$ & $40(55,6 \%)$ \\
\hline AA & $1(2 \%)$ & & $3(4,2 \%)$ \\
\hline Allelic Frequency & & & \\
\hline
\end{tabular}

difference of HDL cholesterol concentration between diabetic patients with and without CAD was not significant.

\section{Genotypic and allelic frequencies of ABCA1 polymorphism in different groups}

The G1051A polymorphism is in Hardy-Weinberg equilibrium in the studied groups. The genotypic and allelic frequencies of the polymorphism are shown in Table 3. The GG genotype seems to be more frequent in diabetic patients compared to control group, however, no significant difference was shown between the different groups. 


\section{Current Research in Diabetes \& Obesity Journal}

\begin{tabular}{|c|c|c|c|}
\hline G & $62,2 \%$ & $70,5 \%$ & $68 \%$ \\
\hline A & $39,8 \%$ & $29,5 \%$ & $32 \%$ \\
\hline
\end{tabular}

Association of G1051A polymorphism with diabetes and CAD

The calculation of the odds ratio (OR) of each genotype between the controls and the patients makes it possible to determine a potential association of the polymorphism with the diabetes. As the frequency of the AA genotype is very low in our studied population (only 4 subjects with this genotype out of 172 subjects), the genotype AA was eliminated. Our results highlighted a significant association of GA and GG genotypes with diabetes (Table 4).

Table 4: Association of ABCA1 Gene Polymorphism (G1051A) with Diabetes.

\begin{tabular}{|c|c|c|c|c|c|}
\hline Genotype & $\begin{array}{c}\text { Control } \\
(\mathbf{n = 4 8 )}\end{array}$ & Patients (120) & OR & IC & $\mathbf{p}$ \\
\hline GA & $35(72,9 \%)$ & $70(58,3 \%)$ & 0,52 & $\begin{array}{c}{[0,25-} \\
1,08]\end{array}$ & 0,062 \\
\hline GG & $13(27,1 \%)$ & $50(41,7 \%)$ & 1,92 & $\begin{array}{c}{[0,91-} \\
3,93]\end{array}$ & 0,052 \\
\hline
\end{tabular}

The GA genotype was found to be a protective factor against diabetes ( $\mathrm{OR}<1$ and $\mathrm{p}$-value close to significant value). While the GG genotype appeared as a predisposing factor to diabetes (OR> 1 and the value of $p$ very close to the significant value) (Table 4). However, there is no association between G/A genotypes and CAD (Table 5).

Table 5: Association of ABCA1 Gene Polymorphism (G1051A) with Coronary Artery Disease.

\begin{tabular}{|c|c|c|c|c|c|}
\hline Génotype & Diabetics (51) & $\begin{array}{c}\text { Diabetics } \\
\text { with CAD } \\
\text { (69) }\end{array}$ & OR & IC & $\mathbf{p}$ \\
\hline $\mathrm{AG}$ & $30(58,82 \%)$ & $40(58 \%)$ & 0,96 & $\begin{array}{c}{[0,42-} \\
1,8]\end{array}$ & 0,854 \\
\hline $\mathrm{GG}$ & $21(41,18 \%)$ & $29(42 \%)$ & 1,03 & $\begin{array}{c}{[0,46-} \\
1,9]\end{array}$ & 1 \\
\hline
\end{tabular}

\section{Association of G1051A polymorphism with lipid profile}

To study the effect of G1051A polymorphism on lipid profile, we compare lipid parameter concentration between GG and GA polymorphism in diabetics with and without CAD separately (Table 6). The results showed increased cholesterol and cholesterol LDL concentrations in GG genotype group. Also, apo B concentration increased in GG genotype only in diabetics without CAD and apo A concentration increased in GA genotype only in diabetics with CAD (Table 6).

\section{Discussion}

The ABCA1 (ATP Binding Cassette subfamily A member 1) or also called CERP (Cholesterol Efflux Regulating Protein) was discovered as lipid carrier in 1999, it plays a key role in cholesterol efflux, the first step of reverse cholesterol transport
[11]. Many polymorphisms in ABCA1 gene have been described and were shown to be or not associated with lipid parameters especially HDL cholesterol [9]. The G1051A polymorphism is located in exon 7 of the gene. It causes a change in protein sequence (arginine to lysine in residue 219) in the extracellular domain. It was well studied in many populations with different results in genotype frequencies and its association with lipid profile and disease (Table 7). The studied diseases are known to be associated with lipid profile perturbations (diabetes, CAD, Alzheimer...). The difference in results could be explained by environmental changes between the studied population such as smoking, life style, food, other genetic variants...In fact, the relationship between genes implicated in lipid metabolism and diabetes and CAD was investigated in many previous studies [24-26]. Such studies aim to better understand, prevent and manage diabetes.

In our study, the allele and genotype distributions were almost similar in healthy subjects, diabetic patients without CAD and diabetic patients with CAD and the most frequent allele was $\mathrm{G}$ allele. However, when we compare healthy subjects with all diabetic patients, the results showed that GG genotype is more frequent in diabetic patients and was associated with increased risk of diabetes. But, no association of the polymorphism and CAD was shown.

The analysis of our results showed a significantly higher concentration of total cholesterol, LDL cholesterol and ApoB in diabetics with the GG genotype compared to those with the GA genotype. We can therefore think that the disturbances of lipid metabolism in diabetics were accentuated by the presence of the GG genotype. In this context, calculating the odds ratio of each genotype between controls and patients, found the GG genotype as a predisposing factor to diabetes, and the GA genotype as a protective factor against this disease. These results allowed us to assume that the $\mathrm{G}$ allele of the G1051A polymorphism predisposes diabetes. In fact, in $\beta$ cells, the cholesterol transporter, ABCA1, is involved in cholesterol hemostasis and also in the secretion of insulin [27]. It is likely that this allele gives a weak interaction between ABCA1 and ApoA1, which decreases cholesterol efflux. Alteration of cholesterol levels in plasma and Langerhans islets contributes to island dysfunction and subsequent disruption of insulin secretion [27]. In type 2 diabetic patients with CAD, GG genotype is associated with higher concentration of total cholesterol and LDL cholesterol and lower level of apo A1compared to GA genotype. Furthermore, the decreased level of HDL cholesterol in type 2 diabetics with CAD compared to those without CAD was shown only in GG genotype. However, there was no association between genotypes and CAD. The lack of association may be due to methodological factors such as the sample size, which is in our case relatively small, or 


\section{Current Research in Diabetes \& Obesity Journal}

the difference in the sex ratio between the groups, which is very significant $(\mathrm{p}<0.001)$.

\section{Conclusion}

The G1051A polymorphism of ABCA1 gene was associated with diabetes predisposition. The GG genotype genotype was associated with lipid perturbation. However, no association of this polymorphism and CAD in type 2 diabetes was shown. Further studies are needed to explore the effect of lipids in such associations.

\section{Acknowledgments}

This study is a part of research program of the Research Unit LR12ES05 "Nutrition- functional food and Vascular Health LRNAFS" and "DGRST-USCR- Mass Spectrometry" financed by the Ministry of Higher Education and Scientific Research (Tunisia).

The authors declare no potential conflicts of interest with respect to the research, authorship, and/or publication of this article.

Table 6: Association of ABCA1 Gene Polymorphism (G1051A) with Coronary Artery Disease.

\begin{tabular}{|c|c|c|c|c|c|c|}
\hline & \multicolumn{2}{|c|}{ Diabetics without CAD (51) } & \multirow[t]{2}{*}{$\mathbf{p}$} & \multicolumn{2}{|c|}{ Diabetics with CAD (69) } & \multirow{2}{*}{$\mathbf{q}$} \\
\hline & GG (21) & GA (30) & & GG (29) & GA (30) & \\
\hline $\operatorname{Sex}(M / F)$ & $\begin{array}{l}8(38,1 \%) / \\
13(61,9 \%)\end{array}$ & $\begin{array}{c}13(43,3 \%) / \\
17(56,7 \%)\end{array}$ & 0,77 & $\begin{array}{c}24(82,8 \%) / \\
5(17,2 \%)\end{array}$ & $\begin{array}{l}24(60 \%) \\
/ 16(40 \%)\end{array}$ & 0,06 \\
\hline Age (years) & $51,76 \pm 6,09$ & $50,93 \pm 6,280$ & 0,64 & $56,14 \pm 6,901$ & $56,05 \pm 7,264$ & 0,95 \\
\hline BMI (kg/m2) & $28,5[24,33-32,05]$ & $27,2[25,22-31,73]$ & 0,81 & $27,7[25,3-30,4]$ & $\begin{array}{c}29,67[27,63- \\
32,05]\end{array}$ & 0,87 \\
\hline $\begin{array}{l}\text { Cholesterol } \\
(\mathrm{mmol} / \mathrm{l})\end{array}$ & $5,38 \pm 1,10$ & $4,92 \pm 0,79$ & 0,06 & $5,06 \pm 0,18$ & $4,61 \pm 1,06$ & 0,02 \\
\hline $\begin{array}{l}\text { HDL cholesterol } \\
(\mathrm{mmol} / \mathrm{l})\end{array}$ & $0,9 \pm 0,24$ & $0,81 \pm 0,24$ & 0,16 & $0,76 \pm 0,23$ & $0,81 \pm 0,15$ & 0,83 \\
\hline $\begin{array}{l}\text { LDL cholesterol } \\
(\mathrm{mmol} / \mathrm{l})\end{array}$ & $3,60 \pm 0,73$ & $3,17 \pm 0,84$ & 0,06 & $3,51 \pm 0,82$ & $3,04 \pm 0,83$ & 0,06 \\
\hline Apo B (g/l) & $1,16 \pm 0,28$ & $0,99 \pm 0,24$ & 0,03 & $0,96 \pm 0,17$ & $1,06 \pm 0,25$ & 0,24 \\
\hline ApoA1 (g/l) & $1,43[1,24-1,63]$ & $1,3[1,1-1,48]$ & 0,14 & $1,18[0,93-1,39]$ & $1,36[1,18-1,51]$ & 0,02 \\
\hline $\begin{array}{l}\text { Triglycerides } \\
\text { (mmol/l) }\end{array}$ & $1,42[1,26-2,51]$ & $1,74[1,38-2,76]$ & 0,32 & $1,72[1,43-2,50]$ & $2,08[1,55-2,77]$ & 0,29 \\
\hline
\end{tabular}

p: Difference between GG et GA Genotypes in Diabetics without CAD;

q: Difference between GG et GA Genotypes in Diabetics with CAD.

Table 7: Association between G1051A Polymorphism with Lipid Profile and Many Diseases in Different Populations.

\begin{tabular}{|c|c|c|c|}
\hline Population & Association with Lipid Profile & Studied Diseases & References \\
\hline China & No association & $\begin{array}{c}\text { No association with lacunar infarction combined with } \\
\text { arteriosclerosis }\end{array}$ & {$[16]$} \\
\hline & Association with HDL cholesterol & - & {$[8]$} \\
\hline Iranian & No association & Association with CAD and its severity & {$[17]$} \\
\hline Hungary & - & Association with Alzheimer's disease & {$[19]$} \\
\hline China & Association with apo AI & No association with type 2 diabetes mellitus related mild \\
cognitive impairment & {$[20]$} \\
\hline Saudi Arabia & - & Association with CAD & {$[21]$} \\
\hline Malaysian & No association & Association with type 2 diabetes & {$[22]$} \\
\hline Egyptian & - & Association with premature CAD & {$[23]$} \\
\hline Asian & - & Association with type 2 diabetes & {[} \\
\hline
\end{tabular}

\section{References}

1. Parhofer KG (2015) Interaction between Glucose and Lipid Metabolism: More than Diabetic Dyslipidemia. Diabetes Metab J 39(5): 353-362.

2. Lin ZF, Wang CY, Shen LJ, Hsiao FY, Lin Wu FL, et al. (2016) Statin Use and the Risk for Incident Diabetes Mellitus in Patients with Acute Coronary Syndrome after Percutaneous Coronary Intervention: A Population-Based Retrospective Cohort Study in Taiwan. Can J Diabetes 40(3): 264-269.
3. Goldberg IJ (2001) Diabetic Dyslipidemia: Causes and Consequences The Journal of Clinical Endocrinology \& Metabolism 86: 965-971.

4. Cecilia C, Low W, Connie NH, William RH, Allison BG (2016) Atherosclerotic Cardiovascular Disease and Heart Failure in Type 2 Diabetes - Mechanisms, Management, and Clinical Considerations. Circulation 133(24): 2459-2502.

5. Cavelier C, Lorenzi I, Rohrer L, Von EA (2006) Lipid efflux by the ATPbinding cassette transporters ABCA1 and ABCG1. Biochim Biophys Acta 1761(7): 655-666. 


\section{Current Research in Diabetes \& Obesity Journal}

6. Tang C, Oram JF (2009) The cell cholesterol exporter ABCA1 as a protector from cardiovascular disease and diabetes. Biochimica et Biophysica Acta 1791(7): 563-572.

7. Barbaras R, Martinez LO, Jacquet S, Tercé F, Collet X, et al. (2005) HDL receptors and reverse cholesterol transport. Sang Thrombose Vaisseaux 1: 39-46.

8. Mokuno J, Hishida A, Morita E, Sasakabe T, Hattori Y, et al. (2015) ATPbinding cassette transporter A1 (ABCA1) R219K (G1051A, rs2230806) polymorphism and serum high-density lipoprotein cholesterol levels in a large Japanese population: cross-sectional data from the Daiko Study. Endocr J 62(6): 543-549.

9. Singaraja RR, Brunham LR, Visscher H, Kastelein JJP, Hayden MR, et al. (2003) Efflux and atherosclerosis. The clinical and biochemical impact of variations in tha ABCA1 gene. Arterioscler Thromb Vasc Biol 23(8): 1322-1332

10. Benton JL, Ding J, Tsai MY, Shea S, Rotter JI, et al. (2007) Associations between two common polymorphisms in the ABCA1 gene and subclinical atherosclerosis: Multi-Ethnic Study of Atherosclerosis (MESA). Atherosclerosis 193(2): 352-360.

11. Yamakawa-Kobayashi K, Yanagi H, Yu Y, Endo K, Arinami T, et al. (2004) Associations between serum high-density lipoprotein cholesterol or apolipoprotein AI levels and common genetic variants of the ABCA1 gene in Japanese school-aged children. Metabolism 53(2): 182-186.

12. Saleheen D, Khanum S, Haider SR, Nazir A, Ahmad U, et al. (2007) A novel haplotype in ABCA1 gene effects plasma HDL-C concentration. Int J Cardiol 115(1): 7-13.

13. (1997) The expert committee on the diagnosis and classification of diabetes mellitus. Report of the expert committee on the diagnosis and classification of diabetes mellitus. Diabetes Care 26(1): 1183-1197.

14. Smaoui M, Hammami S, Chaâba R, Attia N, Ben Hamda K, et al. (2004) Lipids and lipoprotein (a) concentrations in Tunisian type 2 diabetic patients: relationship to glycaemic control and diabetic complications J Diabetes Complications 18(5): 258-263.

15. Tuoya Y, Yuexi W, Xiaoyu L (2017) Relationship between single nucleotide polymorphism of ABCA1 gene and susceptibility of coronary heart disease in Mongolian/Han population. Int J Clin Exp Med 10: 3478-3485.

16. Yao X, Zhenqiang L (2018) Relationship between ABCA1 gene polymorphism and lacunar infarction combined with arteriosclerosis in patients. Exp Ther Med 16(2): 1323-1327.

17. Ghaznavi H, Aali E, Soltanpour MS (2018) Association Study of the ATP - Binding Cassette Transporter A1 (ABCA1) Rs2230806 Genetic
Variation with Lipid Profile and Coronary Artery Disease Risk in an Iranian Population. Open Access Maced J Med Sci 6(2): 274-279.

18. Fehér Á, Giricz Z, Juhász A, Pákáski M, Janka Z, et al. (2018) ABCA1 rs2230805 and rs2230806 common gene variants are associated with Alzheimer's disease. Neurosci Lett 664: 79-83.

19. Cai R, Han J, Sun J, Huang R, Tian S, et al. (2017) Effects of ABCA1 R219K Polymorphism and Serum Lipid Profiles on Mild Cognitive Impairment in Type 2 Diabetes Mellitus. Front Aging Neurosci 9: 257.

20. Cyrus C, Vatte C, Al-Nafie A, Chathoth S, Al-Ali R, et al. (2016) The impact of common polymorphisms in CETP and ABCA1 genes with the risk of coronary artery disease in Saudi Arabians. Hum Genomics 10: 8.

21. Haghvirdizadeh P, Ramachandran V, Etemad A, Heidari F, Ghodsian $\mathrm{N}$, et al. (2015) Association of ATP-Binding Cassette Transporter A1 Gene Polymorphisms in Type 2 Diabetes Mellitus among Malaysians. J Diabetes Res 2015: 289846

22. Abd El-Aziz TA, Mohamed RH, Hagrass HA (2014) Increased risk of premature coronary artery disease in Egyptians with ABCA1 (R219K), CETP (TaqIB), and LCAT (4886C/T) genes polymorphism. J Clin Lipidol 8(4): 381-389.

23. Jung D, Cao S, Liu M, Park S (2018) A Meta-Analysis of the Associations Between the ATP-Binding Cassette Transporter ABCA1 R219K (rs2230806) Polymorphism and the Risk of Type 2 Diabetes in Asians. Horm Metab Res 50(4): 308-316.

24. Chaaba R, Hammami S, Attia N, Smaoui M, Masmoudi AS, et al. (2005) Association of Plasma Cholesteryl Ester Transfer Protein Activity and Polymorphism with Coronary Artery Disease Extent in Tunisian Type II Diabetic Patients. Clin Biochem 38(4): 373-378.

25. Chaaba R, Attia N, Hammami S, Smaoui M, Mahjoub S, et al. (2005) Association of SNP3 polymorphism in the apolipoprotein A-V gene with plasma triglyceride levels in Tunisian type 2 diabetes. Lipids Health Dis 4: 1 .

26. Chaaba R, Attia N, Hammami S, Smaoui M, Ben Hamda K, et al. (2008) Association Between Apolipoprotein E Polymorphism, Lipids and Coronary Artery Disease in Tunisian Type 2 Diabetes. J Clin Lipidol 2(5): 360-364.

27. Brunham LR, Kruit JK, Bruce Verchere C, Hayden MR (2008) Cholesterol in islet dysfunction and type 2 diabetes. The J Clin Invest 118(2): 403408

\section{Your next submission with Juniper Publishers} will reach you the below assets

- Quality Editorial service

- Swift Peer Review

- Reprints availability

- E-prints Service

- Manuscript Podcast for convenient understanding

- Global attainment for your research

- Manuscript accessibility in different formats

( Pdf, E-pub, Full Text, Audio)

- Unceasing customer service

Track the below URL for one-step submission

https://juniperpublishers.com/online-submission.php 